\title{
UNA POÉTICA INÉDITA DEL SIGLO XVIII
}

\author{
JOSÉ CHECA BELTRÁN \\ Instituto de la Lengua Española \\ CSIC. Madrid
}

En la Biblioteca Nacional de Madrid se halla un manuscrito fechado en 1784 y titulado Tratado de la poesía. Que yo sepa, hasta ahora no ha sido citado ni estudiado por ninguno de los investigadores que se han ocupado de poética o del siglo XVIII en general. Como su título indica ${ }^{1}$, es un tratado sobre la poesía, una poética. Más exactamente, es la primera parte de una poética, la que se ocupa de la "poesía en general»; el manuscrito no contiene la segunda parte - tal y como en su título anuncia-, que habría debido ocuparse de la «poesía en particular», es decir, de cada uno de los géneros poéticos por separado. Mi propósito es dar a conocer y analizar el contenido de este interesante libro, aplazando por el momento una investigación sobre su autoría o sobre la posible existencia de esa segunda parte.

A pesar de las inevitables referencias - más o menos comprometidasa la época en que una obra se escribe, no pueden esperarse de antemano muchas novedades en el contenido de un tratado de poética, al ser ésta una disciplina que suele recoger y repetir con ligeras variantes la tradición teórica clásica. Todo ello se advierte en el Tratado dieciochesco que comentamos. Sin embargo, a mi entender, existen tres motivos que confieren un interés especial a este manuscrito, y que justifican estas páginas. El primero de ellos consiste en la inclusión de un capítulo insólito en los tratados de poética españoles del Setecientos: se trata de unas páginas dedicadas al «entusiasmo», concepto poético descuidado por nuestros tratadistas dieciochescos, y al que nuestro anónimo autor dedica una inusual e inteligente atención. El segundo motivo deriva del hecho de que nuestro autor tomó como fuente la Encyclopédie francesa, algunas de cu-

1 El título completo de la obra, de autor anónimo, es el siguiente: Tratado de la Poesia dividido en dos partes, de las quales en la primera se trata de la Poesia en General, y en la segunda de la misma en particular. Parte primera, año de 1784 . Se trata de un volumen de 143 por $92 \mathrm{~mm}$., con 309 páginas numeradas. Su signatura es Ms. 8126. En mis citas he actualizado las grafías, puntuación, y uso de mayúsculas. 
yas páginas traduce literalmente en su obra. Finalmente, el Tratado copia fielmente muchas opiniones expresadas en la Poética de Luzán. El autor no menciona su fuente en ninguno de los dos casos.

$\mathrm{Si}$ el primer motivo señalado otorga un valor propio a la obra que comentamos, los dos siguientes aportan datos de especial relevancia a la historiografía dieciochesca: la enciclopedia francesa tuvo en España una influencia mucho mayor de la que se piensa ${ }^{2}$; con bastante frecuencia fue seguida, traducida o plagiada en nuestro país; el hecho de estar prohibida, su carácter heterodoxo, así como la pretensión de los autores plagiarios de mostrarse como originales, constituyeron los principales motivos para que sus seguidores no la citasen como fuente, $y$, consecuentemente, para que muchos historiadores no hayan apreciado en su justa medida la importancia de su influencia en España.

En cuanto a la Poética de Luzán, existe un debate entre los dieciochistas acerca de su influjo y difusión durante el siglo XVIII; siempre he sostenido que su influencia fue enorme, aunque sus imitadores no siempre declararan el origen de sus ideas. Que el autor anónimo del manuscrito que comentamos la tuviera como referencia importante y copiara de ella algunas frases literalmente - sin citar la fuente-, abona dicha opinión.

Tras estos necesarios preliminares, doy cuenta ya del contenido del manuscrito, prestando una especial atención a su teoría acerca del «entusiasmo», sin duda la aportación teórica más destacada y original de toda la obra, que se presenta dividida en diez capítulos: el primero de ellos se ocupa del «origen de la poesía y sus progresos», el segundo, del «origen de la poesía entre los españoles desde el tiempo de Augusto», el tercero trata «del nombre de poeta, cualidades que debe tener y de su libertad», el cuarto, «de la división de las artes, y conexión que todas tienen entre sí»; el quinto se titula: «que las artes consisten en la imitación; qué cosa es imitación»; el enunciado del sexto anuncia que «el ingenio no debe imitar a la naturaleza tal cual es», el del séptimo, «que la esencia y caracteres de la Poesía están encerrados en la imitación de la naturaleza». El capítulo octavo trata «sobre qué cosa es imitación, y modo de hacerla»; el noveno sostiene que «las reglas generales de la poesía de las cosas están encerradas en la imitación», y, finalmente, el décimo trata «sobre la materia de la poesía, y divisiones que ésta tiene en particular» ${ }^{3}$.

En síntesis, y a primera vista, observamos que el libro contiene ini-

2 En un artículo anterior ofrecí otros datos que avalaban esta hipótesis: José CHECA BELTRÁN, «Una retórica enciclopedista del siglo XVIII: la Filosofía de la elocuencia de Capmany», en Revista de Literatura, L, 99, 1988, pp. 61-89.

3 Así figuran los distintos capítulos en el índice; sin embargo en el desarrollo del libro hay una pequeña variación: el capítulo IX trata sobre la «materia de la poesía», y el X sobre «las reglas generales de la poesía». Es decir, los capítulos IX y X están permutados. 
cialmente unos apuntes sobre historia de la poesía, su origen y sus «progresos», con un capítulo dedicado exclusivamente a la literatura española; en segundo lugar comprende unas disquisiciones sobre las cualidades que debe reunir un poeta; después se refiere a la división de las artes; a continuación se hallan cinco capítulos dedicados a la imitación; y, por último, el manuscrito se ocupa de la materia de la poesía y de sus géneros. Llama la atención el gran espacio dedicado al asunto de la imitación, pero, como veremos, dentro de ese apartado se estudian también otras cuestiones afines.

Vayamos por partes; el comienzo del librito no puede ser más convencional: la poesía comenzó con los cantos de los pastores; de las chozas y aldeas pasó a las ciudades, utilizándose para enseñar la religión, la filosofía y la moral. Siguen las acostumbradas referencias a los primeros poetas: la poesía de los hebreos, griegos, romanos, etc. La historia de la poesía española comienza en la época de Augusto; en cuanto a la poesía en castellano, distingue nuestro autor cuatro épocas, cuyos límites están señalados por los reinados de distintos monarcas, y cuya perfección define según la tópica metáfora sobre las edades del hombre: niñez, juventud, virilidad y vejez. Muy probablemente la fuente de todas estas ideas sea el libro Orígenes de la poesía castellana, de Luis José Velázquez ${ }^{4}$.

La definición inicial de poeta, «aquel que compone en verso» (p. 48), es excesivamente simplificadora, y nuestro anónimo autor se encargará de matizarla en capítulos siguientes. Igualmente sencilla es su catalogación de los distintos poetas: antiguos y modernos según la época en que vivieron, y griegos, latinos, españoles, etc., según el país y lengua correspondiente. Todas estas opiniones, tan simples y esquemáticas, hacen pensar en principio que estamos ante un tratadito para uso de las escuelas; sin embargo las disquisiciones posteriores sobre el entusiasmo o la imitación revelan un conocimiento más profundo de la teoría poética, e inducen a pensar en un destinatario más especializado.

Nuestro autor se desmiente - antes había dicho que poeta es quien escribe en verso- cuando, siguiendo a Boileau, afirma que un poeta necesita del «genio» para diferenciarse del simple versificador. Su definición de «genio» es similar a la que la tradición clasicista ofrecía de «ingenio» ${ }^{5}$, por tanto es inútil intentar hallar similitudes con la idea romántica sobre este concepto. Otro requisito del poeta es el «juicio», la «razón», cualidad necesaria para «no entregarse al fuego de la imaginación» (p. 61), opinión muy en la línea de cualquier tratadista neoclásico. Entre los muchos consejos que la obra ofrece a los jóvenes poetas, figura el de «respetar las costumbres, y no permitirse cosa alguna contra la religión».

4 Luis José VelázqueZ, Orígenes de la poesía castellana, Málaga, oficina de Francisco Martínez de Aguilar, 1754.

5 También se apoya en la idea horaciana de splendida bilis para definir este concepto. 
La libertad del poeta está basada en que no sólo puede representar lo verdadero, sino que también puede inventar ficciones, aunque siempre bajo la guía de la naturaleza: no deberá, así pues, "pintar islas en el aire ni peces en los bosques» (p. 72). Sin embargo, nuestro autor admite lo «maravilloso», y más que una verosimilitud «exterior» —o adecuación de lo escrito con el mundo externo- parece recomendar una «interior», es decir, «una justa relación» entre las distintas partes de la obra ${ }^{6}$. El manuscrito se ocupa a continuación de la división de las «artes», que distingue según su finalidad: primero están las que tienen como objetivo la supervivencia del hombre, después las que buscan su placer y recreo (entre ellas la poesía), y finalmente las que pretenden «la utilidad» (por ejemplo la elocuencia). Como vemos, todo lo dicho se halla dentro de la tradición clasicista más convencional.

El autor comienza sus páginas sobre la imitación afirmando que lo que produce el ingenio «no puede ser sino imitación», por tanto «inventar en las artes no es dar nuevo ser a un objeto, sino reconocerle donde está y como es». Imitar, así pues, es «imitar un modelo», y las artes «no son sino imitaciones» (pp. 83-88). Tras explicar las ideas de Aristóteles (sin citarlo) acerca del natural deseo y gusto humano por la imitación, admite -siguiendo a Boileau - la imitación artística de lo horrendo y monstruoso, ya que el deleite humano no procede de las cosas imitadas, «sino de la perfección del arte que las imita» (p. 98), participando así en el debate acerca de la conveniencia de la representación de «lo feo», discusión que por entonces cobró actualidad a raíz de la publicación del Laocoonte de Lessing. Las principales autoridades clásicas, Aristóteles, Platón y Horacio, sirven a nuestro anónimo autor para justificar el requisito de la imitación, concepto que explica la esencia de la poesía —donde todo es imaginado, fingido, copiado-, distinta de la naturaleza, donde todo es real (p. 107) ${ }^{7}$.

En definitiva, la esencia de la poesía reside en la imitación, pero nuestro autor quiere refutar las opiniones de algunos teóricos sobre este asunto, para lo cual traduce literalmente, sin citarlo, largos párrafos del artículo «poésie» de la Encyclopédie, escrito por Jaucourt: «Algunos han pretendido que ésta [la esencia de la poesía] era la «ficción», pero sin explicar este término no podemos convenir en su significación. Si por «ficción» entienden lo mismo que «fingir» o «fingere» entre los latinos, la palabra «ficción» no debe significar, sino la imitación artificial de los caracteres, costumbres, acciones, discursos, etc., de suerte que fingir será lo mismo

6 El poeta, además, no debe mostrarse muy ingenioso, aunque sí ha de renunciar a la medianía; debe agradar, y debe ejercitar el entendimiento.

7 Sigue con la diferencia aristotélica entre Poesía e Historia -y la consiguiente distinción entre lo verosímil y lo verdadero-, y con la recomendación de que la imitación no sea «servil» - algo sobre lo que unos años despues teorizaría profundamente Esteban de Arteaga-, aduciendo al respecto el tópico ejemplo de Zeuxis. 
que «representar», o más bien «contrahacer», y entonces esta opinión viene a decir lo mismo que lo que nosotros hemos establecido» $(127-129)^{8}$. A este párrafo transcrito siguen algunas páginas más en las que nuestro anónimo autor continúa tratando de las características y las diversas interpretaciones acerca de la ficción, todo ello traducido fielmente de la Encyclopédie, fuente que, como digo, no menciona en ningún momento.

Que la esencia de la poesía se halle en la versificación - debate antiguo sobre el que especuló Luzán, originando su célebre controversia con el Diario de los Literatos - también es negado por nuestro autor, cuyas ideas sobre este argumento están traducidas igualmente de la enciclopedia francesa ${ }^{9}$, a veces intercalando frases de su cosecha o tomadas de otro lugar.

Pero lo que hace más atractivo el tratado de poética que comentamos es el hecho de desarrollar una breve teoría sobre el «entusiasmo», algo que, como ya hemos anticipado, falta en la generalidad de las poéticas españolas del siglo XVIII (excepto en la de Burriel ${ }^{10}$ ). Nuestro manuscrito también se sirve en este apartado del artículo «Poésie» de Jaucourt, concretamente cuando niega que el entusiasmo constituya la esencia de la poesía, ya que éste conviene «también a la prosa, puesto que la pasión no menos sube con todos sus grados a las tribunas que a los teatros» ${ }^{11}$, y cuando rebate a quienes sostienen que el entusiasmo y la pasión «son una misma cosa, y el fin de la poesía es producir el afecto, mover y agradar. [...] Lo concedo si pretenden que la causa, el fin y el medio sean una misma cosa...» (pp. 173-174) ${ }^{12}$.

8 Se trata de una traducción literal de la enciclopedia francesa: «il y a différents opinions sur l'essence de la «poésie»; quelques-uns font consister cette essence dans la fiction. Il ne s'agit que d'expliquer le terme, et de convenir de sa signification. Si par «fiction», ils entendent la même chose que «feindre» ou «fingere» chez les Latins; le mot de «fiction» ne doit signifier que l'imitation artificielle des caracteres, des moeurs, des actions, des discours, etc., tellement que «feindre» sera la même chose que «représenter» ou «contrefairre»; alors cette opinion rentre dans celle de l'imitation de la belle nature que nous avons établie en définiant la "poésie» (Encyclopédie ou dictionnaire raisonné des sciences des arts et des metiers, mis en ordre et publié par M. Diderot, Paris, 1751-1772. La cita en el tomo XII, 1765, p. 100).

9 Para no ocupar innecesariamente un excesivo espacio, me eximo de transcribir aquí los párrafos originales de la enciclopedia francesa y los traducidos en el manuscrito; el lector interesado deberá acudir al artículo «Poésie» (Encyclopédie, tomo XII, 1765, p. 100).

10 Antonio Burriel, Compendio del Arte Poética, Madrid, s.i., 1757.

11 «mais cette qualité ne convient-elle pas également à la prose, puisque la passion avec tous ses degrés ne monte pas moins dans les tribunes que sur les théatres [[...]? (Encyclopédie, op. cit., p. 101). Continúan otros párrafos igualmente traducidos de la enciclopedia.

12 «Mais, dira-t-on, l'enthousiasme et le sentiment sont une même chose, et le but de la «poésie» est de produire le sentiment, de toucher et de plaire; [...] Oui, si l'on veut que la cause et l'effet, la fin et le moyen soient la même chose...» (Ibid., p. 101). 
No fue unánime la posición de los tratadistas de poética acerca de si el entusiasmo era o no un constitutivo esencial de la poesía. Se debe a Platón la primera teoría profunda sobre sus características: los poetas «inspirados» escriben sus obras poseídos por la divinidad; en el estado de arrebato y enajenamiento que caracteriza al entusiasmo, el poeta es un simple e involuntario intermediario entre el mundo divino y la obra de arte. La presencia de la divinidad en el alma del artista determinó que éste fuera denominado alter Deus en el Renacimiento. Las versiones platónica y neoplatónica de esta teoría afectaban al tipo de divinidad causante del entusiasmo.

Pero también se pensó que en el origen del entusiasmo se hallaba la razón. Marsilio Ficino, en una de sus opiniones sobre este concepto, consideró que la obra de arte es producto tanto del entendimiento como de las «operaciones provocadas por la intervención de Dios y el mundo angélico» ${ }^{13}$. Desde la teoría inicial que otorgaba al entusiasmo una procedencia divina, se progresó hacia otra que desvirtuaba su esencia original y atribuía a dicho fenómeno una ascendencia humana, racional. Estos son los dos polos opuestos de la cuestión: origen divino y origen humano; en el siglo XVIII el entusiasmo sería interpretado mayoritariamente como producto de la razón del poeta.

Junto a esta doble explicación acerca del linaje del entusiasmo, éste suele definirse como un fenómeno mediante el cual el poeta se identifica con lo que poetiza, los objetos ausentes devienen presentes, el poeta ocupa el lugar de su personaje, toma su alma. Por otra parte, se especula también con el traspaso del entusiasmo desde el poeta al receptor: de esta manera, en este fenómeno aparecen ya involucrados el dios, el poeta y el público.

Pero el debate dieciochesco sobre este fenómeno se centra en su origen. No sólo se rebate su procedencia «divina», sino también que su causa sea la locura: en efecto, también existieron interpretaciones que veían en el delirio o locura del poeta la fuente del entusiasmo; muchos autores ilustrados reaccionan explicando que el proceso creativo es totalmente racional. La poesía no es algo sagrado, pero tampoco es algo «maldito». Ante el peligro de que el poeta sea considerado de nuevo (tras el precedente platónico) como indigno, inútil, inmoral, loco, se reacciona explicando que el entusiasmo tiene como causa primera la razón, y se atribuye al poeta la respetable condición de filósofo, pensador.

Es en el marco de estas opiniones donde deben inscribirse las reflexiones de nuestro autor anónimo acerca del entusiasmo. Para definirlo, refiere cómo algunos sostienen que éste consiste en una «visión celestial, una

13 Antonio MARí, Euforión. Espíritu y naturaleza del genio, Madrid, Tecnos, 1989, pp. $42-43$. 
influencia divina, y un Espíritu Profético, según otros es una como embriaguez, un éxtasis o enajenamiento, y una alegoría mezclada de turbación y admiración en presencia de la divinidad» (pp. 145-146). Pero en el fondo de estas dos supuestas interpretaciones late una sola, que atribuye al entusiasmo un origen extranatural, divino. La respuesta de nuestro incógnito autor no puede ser más laica: rebate estas opiniones, de «lenguaje tan enfático», porque pretenden «quitar a los profanos los misterios de las musas»; es decir, también los escépticos de la divinidad pueden experimentar el entusiasmo. Por ello se adhiere a la opinión de «un filósofo» (cuyo nombre no proporciona), para sostener que al igual que la divinidad que anima a los héroes en los combates no es más que la audacia, una «intrepidez natural», en los poetas es «un grande caudal de ingenio, una exactitud exquisita de juicio, y sobre todo un corazón lleno de noble fuego». Estos poetas, almas privilegiadas, «se impresionan fuertemente de las cosas que conciben, y no dejan jamás de reproducirlas con un nuevo carácter de gusto y fuerza, que les comunican» (pp. 147-150). Dicho de otra manera, el origen del entusiasmo no es divino, sino humano, concretamente se debe al ingenio y al juicio, facultades naturales. Como se ve, es una interpretación «filosófica», laica, que revaloriza el papel del creador artístico, no ya un simple intermediario de la divinidad, ni un loco, sino un ser dotado de una gran capacidad para razonar e imaginar.

Una vez hallado su origen, nuestro autor afronta su definición: «Una viva representación del objeto en el entendimiento, y una agitación y movimiento extraordinario del corazón proporcionado a el tal objeto» (p. 151). La cultura previa del poeta, así como el buen uso de su imaginación son imprescindibles: «los objetos del entusiasmo consisten en que conociendo el poeta todas las propiedades y perfecciones de que pueden componerse las más bellas imitaciones, cuando se propone imitar alguna cosa, hace allá en su entendimiento un conjunto de todas aquellas perfecciones, concibe de la tal cosa u objeto una idea vivísima, a su vista se enciende al instante su fuego; olvídase de cualquier otro objeto, pasa su alma a las cosas que ha creado en su fantasía, y viene a ser sucesivamente un Cinna, un Augusto, un Phedro y un Hippolito. Y si es un fabulista, él es un lobo, un cordero, una encina, una zorra. En este ímpetu y arrebatamiento es en el que Homero veía los carros y los briosos caballos de los dioses, en el que Virgilio oye los tristes alaridos de Flegias en las tinieblas infernales, y en el que uno y el otro hallan cosas que no hay en ninguna parte, pero que son verdaderas [...]. Esto es lo que llama Cicerón mentis viribus [...]. Este es el furor poético, este es el entusiasmo, este es el Dios que el poeta invoca en la epopeya, que inspira al héroe en la tragedia [...], y en fin, el Dios que hace a los verdaderos poetas" (pp. 151-159). Evidentemente, ese Dios - según nuestro autor- no es más que el conocimiento y la imaginación del poeta; no existe - repito- 
una explicación divina del entusiasmo, sino puramente humana, natural, racional.

Gracias a esa viva representación, que el poeta consigue merced a sus cualidades naturales -el poeta conoce las propiedades de los objetos, y las elabora y concibe de una manera nueva en su entendimiento-, éste se transmuta en aquello que pretende representar. Este es el efecto del entusiasmo: si los poetas quieren pintar una batalla «se trasladan al lugar del combate, oyen el estruendo de las armas, los gritos de los que mueren, ven el furor de unos con otros, la carnicería y la sangre» (p. 156).

Tras analizar las causas, medios y efectos del entusiasmo, nuestro autor aborda muy brevemente otro aspecto sobre este concepto: se trata de decidir si el poeta «debe experimentar en sí mismo el afecto o pasión que quiere producir en los otros»; su respuesta es afirmativa si se sostiene que «la causa, el fin y el medio sean una misma cosa» (p. 174); una conclusión muy ambigua que deja ápenas esbozado el papel que juegan los distintos participantes en el proceso que rodea al entusiasmo ${ }^{14}$.

Pero el interés del desconocido autor del Tratado se centra en la definición de «poesía»: tras describir el concepto de entusiasmo, niega que éste sea el elemento esencial y distintivo de la poesía, ya que también se presenta en la prosa, en los oradores; sigue en este punto la opinión de Batteux, reproducida por Jaucourt en la enciclopedia, fuente directa del autor del manuscrito, quien, en consecuencia, concluye que la poesía es esencialmente imitación, aunque también «encierra el entusiasmo, la ficción o fábula, y aun la versificación, como medios necesarios para imitar perfectamente los objetos» (p. 175). Finalmente ofrece su definición de poesía: «imitación de la naturaleza en lo universal o en lo particular, hecha en versos para el deleite o utilidad de los hombres, o para uno y otro juntamente» (pp. 175176); se trata exactamente de la misma definición que diera Luzán en su Poética ${ }^{15}$ : en su afán por copiar la definición luzaniana, nuestro autor omite los requisitos de la ficción y el entusiasmo, que antes ha considerado integrantes de la poesía, y ha añadido la finalidad de ésta (deleite y utilidad), aspecto éste que no ha tratado en sus anteriores reflexiones. Ello demuestra que el anónimo escritor se dedicó a hilvanar una serie de textos ajenos, que después no supo cohesionar y sistematizar con la perfección deseable.

A continuación explica detalladamente los pormenores de la definición de Luzán, siguiendo puntualmente las palabras de éste acerca de los poetas líricos, la imitación particular y universal, la prosa, y la finalidad de la

14 Más información sobre el «entusiasmo» en el capítulo correspondiente de mi libro Razones del buen gusto. Poética española del neoclasicismo, Madrid, CSIC, 1998.

15 Ignacio DE LUZÁN, La Poética, o Reglas de la Poesía en general, y de sus principales especies, Zaragoza, Francisco Revilla, 1737. Cito por la moderna edición de R.P. Sebold: I. DE LUZÁN, La Poética, Barcelona, Labor, 1977. 
poesía ${ }^{16}$. El capítulo VIII de la obra sigue tratando de la imitación. A partir de ella establece una distinción gramatical acerca de las formas de imitar: exegemática, dramática y mixta, según hable sólo el poeta, los personajes, o autor y personajes. Ideas muy tópicas, pero de nuevo tomadas de Luzán, a quien sigue también en sus breves opiniones sobre la imitación icástica y fantástica ${ }^{17}$.

El capítulo IX trata de la «materia» de la poesía, y de los tipos de ésta ${ }^{18}$. El autor del Tratado considera que «todo aquello a que se le puede suponer acción, todo es materia de la poesía» (p. 224), cuyas acciones pueden ser verdaderas o verosímiles. Los «géneros» o «especies» tienen a su vez subdivisiones; cada uno de los tipos de poesía tienen sus reglas particulares que, anuncia nuestro autor, serán estudiadas en la segunda parte de su obra (p. 220).

En esta primera parte se ocupará sólo de las reglas generales, que «están encerradas en la imitación», tema del capítulo décimo, el último. La primera regla general consiste en «unir lo útil con lo agradable»: tras la obligada cita de Horacio y los conocidos tópicos al respecto, se añaden algunas nociones que reflejan la nueva dirección de los estudios literarios, la interpretación de las obras clásicas a partir de su contexto sociopolítico: «Las poesías de Homero y Virgilio no son vanos romances [...sino], libros nacionales que contienen la historia del estado, el espíritu de gobierno, los principios fundamentales de la moral...» (pp. 244-245). Siguen las repetidas ideas acerca de la lírica lasciva y la honesta, así como sobre la belleza y la dulzura. En todo ello sigue de cerca a Luzán ${ }^{19}$.

La segunda regla general consiste en «que haya una acción en un poema»; es de agradecer que el autor no haya insistido en las consabidas unidades de lugar y tiempo, ya por entonces muy desprestigiadas. La tercera y última regla general pide que la acción sea «singular, una, sencilla y varia»: aquí se permite lo maravilloso y lo alegórico, pero sin faltar a la verosimilitud. Añade el autor que los pasajes y hechos maravillosos de Homero y los antiguos no son aceptables en la literatura actual, ya que lo

16 Ibid., pp. 161-163.

17 Cuando intenta relacionar su triple división de las formas de imitar con géneros históricos concretos, nuestro autor se hace un lío: afirma que si se mezcla la épica y la dramática resulta la tercera especie, que no nombra; y no la nombra porque no le cuadra que la lírica sea la suma de las otras dos especies (evidentemente, quiere decir que la suma de lírica y dramática ocasiona la épica). Por otra parte, su definición de «energía» y «evidencia» también parece proceder de Luzán (op. cit., p. 249).

18 También aquí Luzán (p. 180) sigue siendo la fuente: por ejemplo cuando el autor del manuscrito se refiere (p. 221) al «modo más perfecto de imitar», el modo dramático.

19 LUZÁN, op. cit., pp. 194-195 y 207-211. El tratadista aragonés es seguido hasta en los ejemplos: así el relativo a la madre de Euríalo (Luzán, p. 207; manuscrito, pp. 259-261). 
maravilloso depende «de las ideas recibidas en su siglo» (p. 293); participa así en el debate de entonces acerca del uso de lo maravilloso mitológico por parte de poetas cristianos ${ }^{20}$.

En definitiva, una poética convencional que, sin embargo, supo acudir a las fuentes más seguras y solventes de la teoría literaria de entonces, y que revela por ello - a pesar de algunos desmayos ocasionados por el difícil afán de integrar discursos diferentes - una teoría bastante actualizada del hecho literario, aunque poco desarrollada debido a sus breves páginas. Posee el valor añadido de contar con unas interesantes reflexiones sobre el concepto de entusiasmo, poco difundido en España. Pero, sobre todo, este manuscrito es un documento precioso en la tarea de identificar las principales fuentes de la teoría literaria española de finales del siglo XVIII: no hay duda de que, además de la tradición aristotélico-horaciana, común a la poética de todas las naciones, Luzán - cuya influencia ha sido muy discutida entre los dieciochistas-, la Encyclopédie - fuente que el dieciochismo ha desconocido por lo que se refiere a teoría literaria- y Batteux -este último directamente o a través de la enciclopedia francesa- son tres referencias indispensables y principalísimas para nuestro anónimo autor, y también - tal y como vengo sosteniendo- para todos nuestros teóricos de las últimas décadas dieciochescas.

20 Véase mi artículo «Verosimilitud y maravilla en la poética española dieciochesca», Anthropos, 154-155, 1994, pp. 32-38. 